\title{
PENGARUH BUDAYA PATRIARKI TERHADAP KETERATURAN PEMERIKSAAN KEHAMILAN PADA IBU HAMIL DI WILAYAH PUSKESMAS BANGKALAN
}

\author{
Rodiyatun, Anis Nur Laili, Vicky Ambar Rachmawati \\ Prodi Kebidanan Bangkalan Poltekkes Kemenkes Surabaya \\ Email : rodi.yatun@yahoo.com, zahroulanis@gmail.com
}

\begin{abstract}
ABSTRAK
Antenatal Care (ANC) adalah pemeriksaan kehamilan untuk mengoptimalkan kesehatan mental dan fisik ibu hamil, hingga mampu menghadapi persalinan, kala nifas, dengan frekuensi kunjungan minimal 4 (empat) kali selama kehamilan. Menurut Ditjen Bina Gizi dan KIA, Kemenkes $\mathrm{RI}$ tahun 2013, cakupan K1 mengalami penurunan dari 96,84\% menjadi 95,25\% dan cakupan K4 juga mengalami penurunan dari $90,18 \%$ menjadi $86,85 \%$ dibandingkan tahun sebelumnya. Secara nasional, indikator kinerja cakupan pelayanan kesehatan ibu hamil K4 padatahun 2013 belum dapat mencapai target Rencana Strategis (Renstra) Kementerian Kesehatan, yakni sebesar 93\%.

Jenis penelitian ini merupakan penelitian analitik dengan desain yang digunakan adalah cross sectional yang bertujuan untuk mengetahui pengaruh budaya patriarki terhadap keteraturaan pemeriksaan ANC. Penelitian ini dilaksanakan di wilayah kerja Puskesmas Bangkalan. Populasi dalam penelitian ini 41 ibu hamil. Dalam hal ini peneliti menggunakan jenis Probability Sampling dengan teknik Systematic Random Sampling dimana setiap pasien yang memenuhi kriteria penelitian dimasukkan dalam penelitian sesuai dengan jumlah pasien/ibu hamil pada register (Kohort) ibu hamil. Analisis data dilakukan menggunakan analisis univariate yang dilakukan terhadap masing-masing variabel dari hasil penelitian dan analisis bivariat dengan tabel silang digunakan untuk melihat gambaran pengaruh variabel independen dan dependen yaitu budaya patriarki dan keteraturan kunjungan pemeriksaan kehamilan. Selanjutnya dilakukan uji Chi-Square dengan tingkat kesalahan 0,5 .

Hasil penelitian ini memperlihatkan hasil didapatkan nilai p: 0,075 > a 0,05 maka tidak ada pengaruh budaya patriarki terhadap keteraturan pemeriksaan kehamilan. Perlu adanya upaya optimalisasi program kesehatan untuk meningkatkan pengetahuan tentang pentingnya pemeriksaan kehamilan (ANC) dengan mempermudah akses layanan ANC, memberikan penyuluhan lapangan secara lebih detail dan informatif tidak hanya kepada ibu hamil tetapi juga suami dan anggota keluarga lainnya, serta menghargai budaya yang dianut masyarakat setempat yang tidak mempengaruhi kesehatan.
\end{abstract}

Kata kunci: Budaya Patriarki, Keteraturan Kunjungan, Antenatal Care

\section{PENDAHULUAN}

Pemeriksaan Antenatal Care (ANC) adalah pemeriksaan kehamilan untuk mengoptimalkan kesehatan mental dan fisik ibu hamil sehingga mampu menghadapi persalinan, kala nifas, persiapan pemberian ASI, dan kembalinya kesehatan reproduksi secara wajar (Manuaba, 2008). Kebijakan program pelayanan antenatal menetapkan frekuensi kunjungan antenatal sebaiknya minimal 4 (empat) kali selama kehamilan, dengan ketentuan sebagai berikut (Depkes, 2009): minimal satu kali pada trimester pertama (K1) hingga usia kehamilan 14 minggu, minimal satu kali pada trimester kedua (K2), 14 - 28 minggu, minimal dua kali 
pada trimester ketiga ( $\mathrm{K} 3$ dan K4) 28 - 36 minggu, dan setelah 36 minggu sampai lahir.

Menurut Ditjen Bina Gizi dan KIA, Kemenkes RI tahun 2013, cakupan K1 mengalami penurunan dari 96,84\% menjadi 95,25\% dan cakupan K4 juga mengalami penurunan dari $90,18 \%$ menjadi $86,85 \%$ dibandingkan tahun sebelumnya. Secara nasional, indikator kinerja cakupan pelayanan kesehatan ibu hamil K4 pada tahun 2013 belum dapat mencapai target Rencana Strategis (Renstra) Kementerian Kesehatan, yakni sebesar $93 \%$.

Dari jumlah K1 dan K4 tersebut, didapatkan ibu hamil yang memiliki riwayat obstetrik buruk seperti riwayat perdarahan, ketuban pecah dini, kelainan letak serta preeklampsi cenderung lebih rutin melakukan pemeriksaan kehamilan dari pada ibu hamil yang memiliki riwayat obstetrik baik.

Beberapa kemungkinan penyebab ketidakteraturan pemeriksaan meliputi faktor ibu (pendidikan, pekerjaan, pengetahuan, riwayat kesehatan ibu atau riwayat obstetri), faktor lainnya seperti faktor sosial ekonomi dan budaya. Selain faktor diatas faktor tenaga kesehatan, faktor informasi, faktor pekerjaan, serta sarana dan prasarana termasuk jarak tempuh ke tempat pelayanan kesehatan dari jangkauan sasaran (ibu hamil) turut mempengaruhi perilaku berkaitan dengan pemeriksaan kehamilan.

Faktor budaya merupakan salah satu faktor yang dianggap dominan terhadap perilaku kesehatan. Budaya adalah suatu sistem kognitif, yang terdiri dari pengetahuan, kepercayaan, dan nilai yang berada dalam pikiran individu sebagai anggota masyarakat. Budaya berada dalam tatanan kenyataan yang ideasional berfungsi sebagi perlengkapan mental, yang digunakan dalam proses orientasi, transaksi, pertemuan, perumusan, gagasan, penggolongan, dan penafsiran perilaku sosial nyata dalam tatanan masyarakat (Sulaeman, M. 2012).

Dalam arti lain budaya digunakan sebagai pedoman dalam bertingkah laku dan bersifat turun-temurun hingga apapun tindakan yang akan dilakukan seorang ibu hamil harus sesuai dengan budaya yang dianut. Masyarakat Madura cenderung sebagai masyarakat yang patrilineal dimana posisi laki-laki lebih dominan dibandingkan posisi perempuan. Pengambil keputusan tertinggi apapun dalam keluarga berada di tangan suami. Budaya patriarki diartikan sebagai sistem pengelompokan sosial (masyarakat) yang menempatkan kedudukan bapak atau laki-laki lebih tinggi dari pada perempuan dalam segala aspek kehidupan (Setiadi, dkk., 2007). Dalam tatanan kehidupan keluarga masyarakat Madura, lakilaki cenderung diposisikan sangat superior dan mendominasi terhadap berbagai sektor kehidupan baik domistik maupun publik. Kontrol laki-laki atas perempuan meliputi aspek fisiknya, seksualitasnya, pekerjaannya, peran dan statusnya, baik dalam keluarga maupun masyarakat, dan segala bidang (Halid.E.Mohammad, dkk., 2013). Pada pemeriksaan kehamilan, perempuan diposisikan sebagai subjek, dimana otoritas 
pengambilan keputusan berada pada suami. Hal ini memberi pengaruh langsung terhadap keteraturan seorang ibu hamil dalam melakukan pemeriksaan kehamilannya.

Pemeriksaan kehamilan yang tidak teratur akan berpengaruh pada kondisi ibu dan bayi, karena kurang terpantaunya keadaan ibu sehingga bila terjadi masalah tidak dapat ditangani secara dini dan berakibat terjadinya kehamilan beresiko yang diikuti proses persalinan patologis. Tentu hal ini bisa berdampak pada peningkatan AKI dan AKB. Oleh karena itu diperlukan asuhan kebidanan yang berkesinambungan (continuity of care) dengan melibatkan keluarga, agar ibu meperoleh asuhan secara maksimal selama hamil, bersalin dan masa nifas.

\section{METODE PENELITIAN}

Jenis penelitian yang digunakan adalah observasional analitik dengan rancangan cross sectional. Tujuan penelitian adalah mengalisa pengaruh budaya patriarki terhadap keteraturan pemeriksaan kehamilan pada ibu hamil di wilayah Puskesmas Bangkalan. Penelitian dilaksanakan di wilayah kerja Puskesmas Bangkalan pada bulan Mei-Agustus 2016. Populasi sebanyak 41 orang ibu hamil, dengan simple random sampling dan tehnik sistimatik sampling berdasarkan nomer register kohort ibu hamil didapatkan jumlah sampel sebanyak 37 orang. Sebagai variabel independen yaitu budaya patriarki, terdiri dari sub variabel (1) Pengetahuan (2) Kepercayaan (3) Nilai, sedang variabel dependen adalah keteraturan ANC. Pengumpulan data budaya patriarki menggunakan kuisioner sedangan keteraturan ANC dengan metode dokumentasi berdasarkan buku KIA dan laporan kohort. Analisis dengan analisis univariate untuk mendapatkan gambaran/variasi data dari variabel budaya patriarki dan keteraturan ANC, selanjutnya dengan analisis bivariat dengan tabel silang dan uji Chi-Square.

\section{HASIL PENELITIAN}

\section{Hasil Pengumpulan Data}

1) Keteraturan Pemeriksaan Kehamilan

Tabel 1. Distribusi frekuensi ibu hamil berdasarkan keteraturan ANC di wilayah kerja Puskesmas Bangkalan Tahun 2016

\begin{tabular}{ccc}
\hline Keteraturan ANC & $\sum$ & $\%$ \\
\hline Teratur & 31 & 83,78 \\
\hline Tidakteratur & 6 & 16,22 \\
\hline Total & 37 & 100 \\
\hline
\end{tabular}

2) Sub Variabel Budaya Patriarki

a. Pengetahuan

Tabel 2. Distribusi frekuensi ibu hamil berdasarkan pengetahuan di wilayah kerja Puskesmas Bangkalan 2016

\begin{tabular}{ccc}
\hline Pengetahuan & $\sum$ & $\%$ \\
\hline Baik & 26 & 70,27 \\
\hline Tidak baik & 11 & 29,73 \\
\hline Total & 37 & 100 \\
\hline
\end{tabular}

b. Kepercayaan

Tabel 3. Distribusi frekuensi ibu hamil berdasarkan kepercayaan di wilayah kerja Puskesmas Bangkalan 2016

\begin{tabular}{ccc}
\hline Kepercayaan & $\sum$ & $\%$ \\
\hline Percaya terhadap mitos & 16 & 43,24 \\
\hline Tidak percaya terhadap mitos & 21 & 56,76 \\
\hline Total & 37 & 100 \\
\hline
\end{tabular}


c. Nilai

Tabel.4 Distribusi frekuensi ibu hamil berdasarkan nilai di wilayah kerja Puskesmas Bangkalan 2016

\begin{tabular}{ccc}
\hline Nilai & $\sum$ & $\%$ \\
\hline Positif & 31 & 83,78 \\
\hline Negatif & 6 & 16,22 \\
\hline Total & 37 & 100 \\
\hline
\end{tabular}

3) Budaya patriarki

Tabel 5. Distribusi frekuensi ibu hamil berdasarkan budaya patriarki di wilayah kerja Puskesmas Bangkalan 2016

\begin{tabular}{ccc}
\hline Budaya Patriarki & $\sum$ & $\%$ \\
\hline Ekstrem & 17 & 45,95 \\
\hline Moderat & 20 & 54,05 \\
\hline Total & 37 & 100 \\
\hline
\end{tabular}

\section{Analisis}

1)Tabulasi silang

Tabel.6 Tabulasi silang variabel budaya patriarki dan keteraturan pemeriksaan kehamilan pada ibu hamil di wilayah kerja Puskesmas Bangkalan 2016

\begin{tabular}{cccccccc}
\hline \multirow{2}{*}{$\begin{array}{c}\text { Budaya } \\
\text { Patriarki }\end{array}$} & \multicolumn{2}{c}{ Teratur } & \multicolumn{2}{c}{$\begin{array}{c}\text { Tidak } \\
\text { Teratur }\end{array}$} & \multirow{2}{*}{$\Sigma$} & $\%$ \\
\cline { 2 - 6 } & $\sum$ & $\%$ & $\sum$ & $\%$ & & \\
\hline Ekstrem & 12 & 70,5 & 5 & 29,5 & 17 & 100 \\
\hline Moderat & 19 & 95,0 & 1 & 5,0 & 20 & 100 \\
\hline
\end{tabular}

Tabel tabulasi silang di atas menunjukkan bahwa dari 17 ibu hamil dengan kategori budaya patriarki, sebagian besar $(70,58 \%)$ melakukan ANC secara teratur, demikian juga pada kelompok ibu hamil dengan kategori budaya patriarki moderat (19 orang), sebagian besar (95\%) melakukan pemeriksaan kehamilan secara teratur. Hasil ini menggambarkan bahwa tidak ada pengaruh budaya patriarki terhadap keteraturan pemeriksaan kehamilan.
2) Uji Statistik

Hasil analisis didapatkan nilai $\rho<5$ sebanyak 2 sel (50\%) sehingga uji chi-square nilai ṕ : 0,075 > a 0,05 maka, hipotesa ditolak (H0) tidak ada pengaruh budaya patriarki terhadap keteraturan pemeriksaan kehamilan.

\section{PEMBAHASAN}

Hasil analisa data menunjukkan bahwa sebesar 54,05\% ibu hamil termasuk dalam kategori budaya patriarki moderat artinya perilaku berkaitan dengan pemeriksaan kehamilan tidak mutlak berada di pihak lakilaki dan 45,95\% dengan kategori budaya patriarki ekstrem artinya perilaku berkaitan dengan periksaan kehamilan sepenuhnya mutlak berada di pihak laki-laki, baik dalam kepercayaan maupun nilai yang dianut oleh ibu hamil selama masa kehamilan. Sedangkan pada variabel pemerilksaan kehamilan menunjukkan bahwa sebagian besar (83,78\%) ibu hamil melakukan pemeriksaan kehamilan (ANC) secara teratur dan sebagian kecil (16,22\%) melakukan pemeriksaan kehamilan dengan tidak teratur.

Ibu hamil yang melakukan ANC dengan tidak teratur memiliki rentang usia 21-26 tahun, dengan pendidikan rata-rata SD dan SMP, sedangkan ibu hamil yang melakukan ANC teratur rata-rata dengan pendidikan SMA. Hasil ini menggambarkan bahwa pendidikan formal berkaitan dengan kepatuhan ibu hamil melakukan ANC.

Pendidikan dan pengetahuan yang kurang juga menjadi salah satu penyebab 
ketidakteraturan ibu hamil dalam melaksanakan pemeriksaan kehamilan ke petugas kesehatan (bidan). Ibu yang memiliki pengetahuan kurang tentang kehamilan akan memiliki respon kurang peduli terhadap konidisi diri dan janinnya karena mereka tidak mengetahui bahwa setiap trimester memiliki ancaman komplikasi kehamilan seperti saat TM I bisa terjadi perdarahan, TM II bisa terjadi preeklampsia bahkan eklampsia dan TM 3 bisa terjadi kelainan letak janin sehingga pada setiap awal trimester harus dilakukan screening sebagai suatu upaya deteksi dini terhadap komplikasi tersebut. Screening dilakukan saat ibu melakukan kunjungan kehamilan dengan waktu yang telah ditentukan. Jika terdapat kelainan maka ibu akan segera dirujuk ke fasilitas kesehatan pelayanan kesehatan yang lebih memadai agar ibu mendapatkan intervensi yang cepat dan tepat (Sulistyawati, 2009)

Selain itu budaya yang masih kental yang dianut oleh ibu hamil pada kelompok ini juga menjadi penyebab tidak teraturnya pemeriksaan kehamilan yang dilakukan. Budaya masih menjadi acuan bagi ibu hamil dalam bertindak termasuk melakukan ANC.

Di Bangkalan, khususnya di wilayah sekitar Puskesmas Bangkalan, saat ini sudah banyak bidan sebagai ujung tombak wanita dalam mendapatkan pelayanan kesehatan khususnya pada bidang KIA KB. Di Puskesmas Bangkalan sendiri, dilakukan kunjungan rumah ibu hamil agar setiap ibu hamil mendapatkan pelayanan pemeriksaan kehamilan. Di setiap desanya sudah ada lebih dari satu bidan desa yang telah menjalankan program-program berkaitan dengan kesehatan ibu dan anak termasuk pemeriksaan kehamilan. Saat ini para bidan sedang menggencarkan pelayanan pemeriksaan kehamilan melalui KIE kepada ibu hamil dan keluarga. Tidak hanya di Puskesmas, Pustu, dan BPM, ibu hamil juga bisa melakukan pemeriksaan kehamilan di polindes dan posyandu. Tersedianya tenaga kesehatan (bidan) dan jarak fasilitas kesehatan terhadap rumah masyarakat menjadikan ibu hamil lebih mudah mengakses pelayanan kesehatan terutama pada pemeriksaan kehamilan.

Hasil uji didapatkan nilai $\rho$ : 0,075 > a 0,05 maka tidak ada pengaruh budaya patriarki terhadap keteraturan pemeriksaan kehamilan.

Hasil penelitian ini menunjukkan bahwa masyarakat Madura yang menganut faham patriarki baik ekstrem maupun moderat berpeluang sama untuk melakukan pemeriksaan kehamilan atau ANC secara teratur. Namun pada hasil uji odds ratio didapatkan nilai OR = 7,917 $(95 \% \mathrm{Cl}$ : 0,82276,277) yang menunjukkan bahwa responden yang memiliki budaya moderat berpeluang melaksanakan ANC teratur sebanyak 7,917 kali dibandingkan responden yang memiliki budaya ekstrem.

Modernisasi menjadikan budaya patriarki yang dulu tergolong ekstrem dalam tatanan budaya masyarakat Madura, saat ini menjadi moderat. Pada sebagian besar masyarakat Madura, setiap keputusan yang 
diambil oleh keluarga mutlak berada di pihak laki-laki atau dapat dikatakan pengambil keputusan utama keluarga adalah pihak lakilaki. Namun dewasa ini, keputusan dalam keluarga diambil berdasarkan keputusan bersama antara pihak perempuan (istri) dan pihak laki-laki (suami). Pergeseran budaya ini merupakan dampak dari globalisasi. Pada awalnya globalisasi hanya dirasakan di kotakota besar di Indonesia, namun dengan adanya kemajuan teknologi komunikasi, informasi dan transportasi, globalisasi menyebar keseluruh wilayah di Indonesia dengan sangat luas dan cepat. Globalisasi masuk ke semua aspek kehidupan baik dari bidang sosial, ekonomi, budaya, politik dan kesehatan (Suyanto, Ummi Salamah. 2009).

Kemajuan tehnologi dan globalisasi secara lansung berdampak terhadap perilaku ibu hamil, misalnya kemudahan mendapat informasi tentang kehamilan dari media massa, kemudahan transportasi untuk menjangkau tempat pelayanan kesehatan dan kemudahan lainnya. Hal tersebut memberi pengaruh pada keteraturan pemeriksaan kehamilan yang dilakukan oleh ibu hamil di Madura. Ibu hamil dapat memperoleh kesempatan dalam menentukan pilihan tenaga kesehatan, tempat, dan waktu untuk melakukan melakukan pemeriksaan kehamilan sehingga saat ini pemeriksaan kehamilan di Bangkalan telah terlaksana sesuai dengan jadwal dan teratur. Ibu hamil yang memiliki buadaya patriarki moderat atau ekstrem tetap bisa melakukan kunjungan ANC secara teratur. Tidak ada batasan bagi meraka dalam melakukan ANC sehingga pada hasil penelitian ini didapatkan hasil bahwa tidak ada pengaruh budaya patriarki terhadap keteraturan pemeriksaan kehamilan terutama di wilayah Bangkalan Madura.

\section{SIMPULAN}

Berdasarkan hasil penelitian dapat diambil beberapa kesimpulan. Sebagian besar ibu hamil (83,78\%) melakukan pemeriksaan kehamilan (ANC) secara teratur. Sebesar $54,05 \%$ ibu hamil dengan kategori budaya patriarki yang moderat dan tidak ada pengaruh budaya patriarki terhadap keteraturan pemeriksaan kehamilan.

\section{SARAN}

Perlu adanya upaya optimalisasi program kesehatan untuk meningkatkan pengetahuan tentang pentingnya pemeriksaan kehamilan (ANC) dengan mempermudah akses layanan ANC, memberikan penyuluhan lapangan secara lebih detail dan informatif tidak hanya kepada ibu hamil tetapi juga suami dan anggota keluarga lainnya, serta menghargai budaya yang dianut masyarakat setempat yang tidak mempengaruhi kesehatan.

\section{DAFTAR PUSTAKA}

Baihaqi, A. 2015. Pengertian dan Karakteristik Nilai. Jakarta:Salemba Medika.

Holid.E.Mohammad, Dkk, (2013), Kebudayaan Masyarakat Madura, 
Universitas Islam Madura, Fakultas

Fkip, Jurusan Ppkn, Pamekasan

Manuaba, I.C., Manuaba, I.B.F., \& Manuaba,

I.B.G. (2008). Buku Ajar Patologi

Obstetri, EGC, Jakarta.

Prawirohardjo, S. \& Wiknjosastro, H. 2005.

IImu Kebidanan. Yayasan Bina

Pustaka, Jakarta.

Romauli,S. 2011. Asuhan Kebidanan

Yogyakarta : Numed.

Ruthven, K.K. 1984. Feminist Literary

Studies: An Introduction. University

ofCambridge: Press Syndicate.

Saadawi, Nawal El. 2011. Perempuan dalam

Budaya Patriarki. Yogyakarta:Pustaka

Pelajar.
Suyanto dan Ummi Salamah. 2009. Riset Kebidanan. Jogjakarta : Nuha Offset.

Sulistyawati, A. 2009. Asuhan Kebidanan pada Masa kehamilan. Jakarta: Salemba Medika.

Setiadi, Elly M., Hakam, KA., Effendi, R. 2007. IImu Sosial dan Budaya Dasar. Jakarta. Kencana Prenada Media Group.

Sudibyo, L., Sudiatmi, T., Sudargono, A., Triyanto, B. 2013.IImu Sosial Budaya Dasar.Yogyakarta. Andi Offset.

Sulaeman, M. 2012. Ilmu Budaya Dasar: Pengantar ke Arah IImu Sosial Budaya Dasar/ISBD/Social Culture. Bandung. Refika Aditama 